\section{FLEXIBLE FRAMEWORKS}

\author{
David Jolly \\ Professor, School of Architecture and Design, Pontificia Universidad Católica de Valparaíso \\ Miguel Eyquem \\ Professor, School of Architecture and Design, Pontificia Universidad Católica de Valparaíso \\ Victoria Jolly \\ Student of Masters in Nautical and Maritime Studies, Pontificia Universidad Católica de \\ Valparaíso \\ Photography: Author's archive, Mark West
}

Taking advantage of the Open City laboratory-condition and an ongoing research on flexible formworks, this international collaboration explores working with mortar weight to create complex, continuous bodies in concrete.

KEYWORDS Concrete architecture, prefabrication, reinforced concrete, Open City, CAST

$\mathbf{T}$ his is a creative construction that begins in 2002 with the arrival of the architect Mark West to Ciudad Abierta (Open City) in Ritoque, who resides there for a season together with his family. West's first experiences in Ritoque are artistic: he utilizes fabrics as mortar containers to build sculptural volumes that were later exhibited in the Storefront Gallery in New York. During his stay in the Open City West proposed the possibility of using fabrics as containers of concrete to obtain new architectonic forms. In that moment we were building the IntervalTable, an openair place to receive 100 guests. In the act, we raised two 7 -foot columns and a seat at floor level, all realized with flexible framework: with this achievement a creative relationship began that continues up to the present.

With his return to the University of Manitoba in Winnipeg, Canada, West founded CAST (Center for Architectural Structures and Technology) a laboratory dedicated to the study and experimentation of the flexible frameworks that he continues to direct today and with which we began a prolific collaboration.

\section{FLEXIBLE MOLDS: THE EMPLOYED METHODS}

The employment of flexible membranes as concrete framework is a new methodology that has no notable precedents in Chile. Traditionally the containers for liquid or semi-liquid mortars (plaster, earth, concrete) have been fabricated with rigid materials, from the complex molds for molten metal used in sculpture to the usual rectilinear molds for reinforced concrete. All of these govern the final form of the mortar by means of a material that minimizes deformations. In flexible framework, the wet concrete is contained by a combination of rigid, supporting elements and a membrane that only resists traction. This way, upon receiving the mass of concrete the membrane automatically adopts a gravitational force. This is a mechanical fact that, under similar conditions, generates the same form and is, as such, governable.

The investigation begins by testing what are the possible forms in this combination of heavy mortar and supporting membrane that contains it. The experimentation in the cast laboratory has centered on the formal search for the appropriate combination of membranes and rigid elements; the new element here implies at least two key elements. The first is a new figure, its profile and the continuity of the surfaces it has, given that they are three-dimensional bodies. The second is that these complex bodies are obtained by means of constructive operations of relative simplicity. In other words, the reinforcement of the framework and its filling are made in a brief period of time, that which can be synthesized in one dimension: low cost framework and efficient operability in relation to the complex form obtained. These constructive operations can be applied in two fields. One is that of an artisanal fashion, where each piece is realized on site and is constitutes a single copy. The other is that of industrial fabrication where each element is repeated a large number of times, achieving a guaranteed quality while simultaneously low-cost. Beginning with the experience with the architect West, in Valparaiso, we have experimented with both methods, with the accent placed on the realization of full-scale prototypes, verifiable with habitable use, differing from the cAst laboratory where they are only models. Open City offers the possibility of realizing experimental works of real magnitude: with this experimentation we can confirm the feasibility of this technology in our means.

Thus, the experimentation is initiated with a basic course for conceiving the framework for a desired form. This supposes a test period, working in the studio to try possibilities through trial and error, accumulating the conditions that drive a form and correcting undesirables; it is work with the form that includes discovery. Once a satisfactory scale-model is obtained in plaster, a scale model in concrete is made, and later the full-scale prototype. This last step also has a moment of possible verification before realizing a concrete test, filling the definitive framework with sand: it behaves very similarly to concrete and verifies the accuracy of the designed form.

\section{FIRST COLLABORATIVE EXPERIENCE}

What began as a gesture of hospitality to West in 2002 with the firsts tests was transformed in a field of investigation for this group of architects of the Pontificia Universidad Católica de Valparaíso School of Architecture and Design. The investigation begins by proposing a building that is basically built using concrete with flexible framework: the program is an atelier that has its origin in a poetic act in the dunes of the Open City. The architectural idea is to suspend the building to achieve two simultaneous objectives: to barely touch sand so as to not destroy its natural extension (a plus in itself) and to obtain a favorable resistance to earthquakes, minimizing the energy that the hanging building would receive from the ground.

Mark West developed some scale models in his CAst laboratory in Canada, while the Open City team also built plaster and concrete scale-models to master and adjust the technology of the flexible framework that was received by means of drawings and photos from Canada. Later the construction of full-scale prototypes was tackled in a local industry. The basic premise behind this investigation together with the School of Architecture and Design of the PUCV and CAST is that the scale models realized with flexible framework maintain their form with minimal variations at fullscale; that is, it is possible to build that form obtained in a small plaster model at a larger scale in concrete. The first form obtained is a column composed of four industrial prefabricated elements that in 2003 was mounted on the dune, establishing its foundation and the center that joins them to create a unified element.

\section{SECOND COLLABORATIVE EXPERIENCE}

For the Atelier project we needed beams to cover spans that would make a platform over which the interiors would be raised. West and his team designed a beam in 2004 with a variable section and made a prototype in an industrial plant in Canada. Our team, with the collaboration of engineering specialists Luis Della Valle and Jorge Carvallo, calculated a $12 \mathrm{~m}$ long beam with a variable section following the flexion diagram; this way the structural element responds to the foreseen demands but does not have more section 
than the required, resulting in lighter and more economical element. The variable section is obtained with a rectangle of geotextile fixed on a pair of tables, conveniently combining a rigid structure with the deformable fabric. This simple, low-cost building method obtains a complex form.

\section{THIRD COLLABORATIVE EXPERIENCE}

After obtaining the column and the beam, we can now raise a more complex element, a portico: a pair of beams suspended between two composed columns. The company INDHERCo facilitated its installations and experience to obtain elements with industrial quality: 8 components of the columns and the two variable-section beams were made at its plant. On this occasion, the flexible framework proved its capacity for reuse: only one textile piece was used for the 8 vertical elements and another for the two beams since casting over the framework -if laid horizontally- allows for the fabric to be easily removed after setting.

For the mounting operation of these elements, the engineering team made specifications and defined the corresponding steel cable; later a joint for regulating between the beam and the steel cable was designed and built, to support the beams. They were successfully suspended from the pair of columns, the situation in which the portico has been since 2005. For the construction of a building with a suspended concrete structure, an artificial fiber cable unaffected by the corrosion of the salty air of the coast must be found: the technical solution has not yet been found and has detained the progress of the work.

\section{NEW COLLABORATIVE EXPERIENCES}

In 2006, the School of Architecture and Design of the PUcv held a lecture-seminar where Mark West and the local docent team conducted demonstrative experiences of the variety of applications for the flexible frameworks and their contribution to architectonic form. That year a bulge wall was built forming part of the work of the Calzadas del Agua in Open City, giving form to a three-dimensional element that includes volumes and forms within the wall plan, achieved in a single pouring of concrete; with this experience the possibilities for flexible frameworks combined with rigid planes were diversified.

\section{PROJECTIONS OF CONCRETE WITH FLEXIBLE FRAMEWORKS}

This research team has made several monolithic elements in concrete: urban furniture, civil works and donated works in the context of the Travesías, trips around America given once a year by the School of Architecture and Design of the Pontificia Universidad Católica de Valparaíso, a moment when students and faculty members undertake design-build collaborations on site. It is also fitting to highlight a virtue of this technology: specific to this is the use of a fabric that resists the liquid concrete until is sets. Today there are high-resistance, low cost geotextiles on the construction market optimal for use as flexible frames. These textiles are characterized by their lightness making them appropriate for use in a business like the Travesía, usually related to long-distance travel.

And at the possibility of construction in different places we have counted on the collaboration of the Test Laboratory of the PUcv by means of the engineer Gabriela Palma Rojas, who had calculated the doses for each work in both Chile and abroad, guarantying the quality of the concrete.

Furniture for a garden in Garupá. Posadas Misiones, Argentina, 2003 This project consists of horizontal and monolithic volumes that constitute the furniture of the garden for a cafeteria for children at risk. The design and construction of elements support the body in the middle of the garden: they are pauses and places for child recreation, of organic forms. This work was made during a Travesía by the second year studio with the collaboration of the architects, Fernando Espósito and Claudio Villavicencio.

Table for a Plaza in São Miguel das Missoes, Brazil, 2006

It is the construction of a public space that allows the gathering of the inhabitants of the former Mission with those who arrive, cultural tourists that visit the place. The mayor and the tourist agents agree that a public table could initiate a relationship that up until now has not had its own space. So, a cross-form table was built using flexible framework in a week of work with the architecture studio. Each section of the table is a monolithic element made with a single concrete pouring. This work was made during a Travesía done by the fourth year architecture studio with the participation of the architects Patricio Cáraves and David Jolly.

Place for a pause in the desert of Atacama, Chile, 2009

This is an in situ design in the Pan de Azucar National Park consisting of volumes that, without interrupting the wildness of the desert landscape, create a place to stop and receive the bodies for the contemplation of this singular extension. Due to the use of dry aggregates available on site, resulting textures and colors do not contrast with the natural environment.

Plaza de Gualliguaica in the Valle de Elqui, Chile, 2010

The recently moved and refounded the village of Gualliguaica (after the construction of the Puclaro reservoir) has a site designated for a plaza that still lacks the character of an inhabitable place. The Travesía that is done here raises the first elements that allow for pausing and remaining in the public plaza. Concrete seats are designed and built with a form obtained by flexible framework. During one week, the fifth year architecture studio with the collaboration of the diploma project student Néstor López raises six elements that initiate the civil space; elements that, with its form, are posed on a sloped plan in the plaza giving it a first habitability in its useful dimension (a place to sit) as well as its visual dimension (the presence of a form in the space).

Coastal border Loncura Quintero, Chile, 2011

Located in the urban space of the central coast, between Quintero and Loncura, this urban fixture - in project stage- was conceived with flexible frameworks realized with the collaboration of the diploma project students Valeria Valenzuela and Felipe Gaymor. In it elements were designed to give form to the limit between path and the beach of the Quintero bay; these monolithic elements cover the character of the urban fixture allowing for the proximity of the bodies with its finished surface and at the same time make up a defense on the border. Each one is a concrete volume that does not require steel reinforcement, guaranteeing its durability in highcorrosion environment due to the presence of the salty humidity of the sea. Six different modules were designed that could be placed one after another, generating variations in the continuous figure of the limit between the beach and the path.

\section{Loncura Civic Center Amphitheater, Chile, 2010}

A work conceived and realized with monolithic concrete elements: its form and finishes obtained with flexible framework in an industrial fabrication process, guaranteeing a homogenous quality and economy of scale in its production. The conception of a concrete, urban fixture 
with these characteristics has special interest in many ways: material durability, it does not present the fragility of wood or plastic, it is fireproof and due to its mass it is unsusceptible to vandalism. Its form tends toward a harmonic whole with the open-air environment.

COLLABORATIVE RESEARCH: CONCLUSIONS AND CERTAINTIES The investigation and experimentation with the flexible frameworks, in both the controlled atmosphere of the CAsT laboratory, urban sites and more remote places such as parks and natural extensions, allow us to ascertain some things about them.

Supported in the correspondence between the small plaster models and the full-scale form in concrete we have verified the following ideas related to the flexible framework:

-With regards to the form, it is possible to create figures that with traditional rigid framework would be incredibly high cost.

-It is possible to obtain a high quality finished surface with regards to its texture and continuity even in double-curved surfaces.

-The use of permeable textile tends to improve the quality of the concrete: this framework allows possible excesses of water in the mixture to drain while leaving the cement.

-With regards to a formal property (that can be qualified as subjective, but nonetheless it has a clear value): the bodies formed by double-curved planes are easily associated with organic structures and are visually joined as parts of an organism. This means that the form is perceived as less invasive, less aggressive and therefore more harmonious with the natural surroundings and even with the artificial environments of urban spaces.

-To obtain with simple constructive processes a new form for architecture is for us an opening for the use of this technology when the occasion permits or requires.

-The simplicity of the design of the framework and the possibility for reuse verifies it as a low-cost technology in relation to the formal quality of the object that can be obtained.

Finally, it is fitting to highlight the fertility that a collaboration of this nature has generated where two centers of studies have coincided: the CAST laboratory in Canada and the School of Architecture and Design of the PUCv in Chile, with the sponsorship of the Amereida Corporation that gives space for the works in the Open City. It is the built work that permits a real interdisciplinary connection. ARQ

Suggested bibliography

PALMER, Montserrat y Patricio MARDONES (eds.). Hormigón en obra. Ediciones ARQ, Santiago, 2009. Storefront for art and architecture: http://www.storefrontnews.org/exhibitions_events/all?t=445 CAST: http://www.umanitoba.ca/cast_building/

\section{David Jolly}

Architect, Pontificia Universidad Católica de Valparaíso, 1977 and Doctoral candidate for the Escola Tècnica Superior d'Arquitectura de Barcelona de la Universitat Politècnica de Catalunya. $\mathrm{He}$ is a member and co-founder of the Amereida's Ciudad Abierta in Ritoque and co-author of Travesías por América from 1984 to present. He was director of the School of Architecture and Design of the PUCV from 1998 to 2003 and dean of the Faculty of Architecture and Urbanism of the same university from 2006 to 2009. He is currently professor in the School of Architecture and Design of the Pontificia Universidad Católica de Valparaíso.

\section{Miguel Eyquem}

Architect, Pontificia Universidad Católica de Chile, 1950 and Doctor Honoris Causa, Pontificia Universidad Católica de Valparaíso, 2009. He is member and co-founder of the Amereida Ciudad Abierta in Ritoque and co-author of Travesías por América from 1984 to present; his research includes the area of constructive systems besides projects and aeronautical constructions. $\mathrm{He}$ is currently professor in the School of Architecture and Design in the Pontificia Universidad Católica de Valparaíso.

\section{Victoria Jolly}

Architect, Pontificia Universidad Católica de Valparaíso, 2007. She is member of the Amereida Ciudad Abierta in Ritoque; between 2007 and 2008 she was assistant professor for architecture studios in the School of Architecture and Design of the Pucv. Currently she is a student of the Masters in Nautical and Maritime studies at the Pontificia Universidad Católica de Valparaíso.
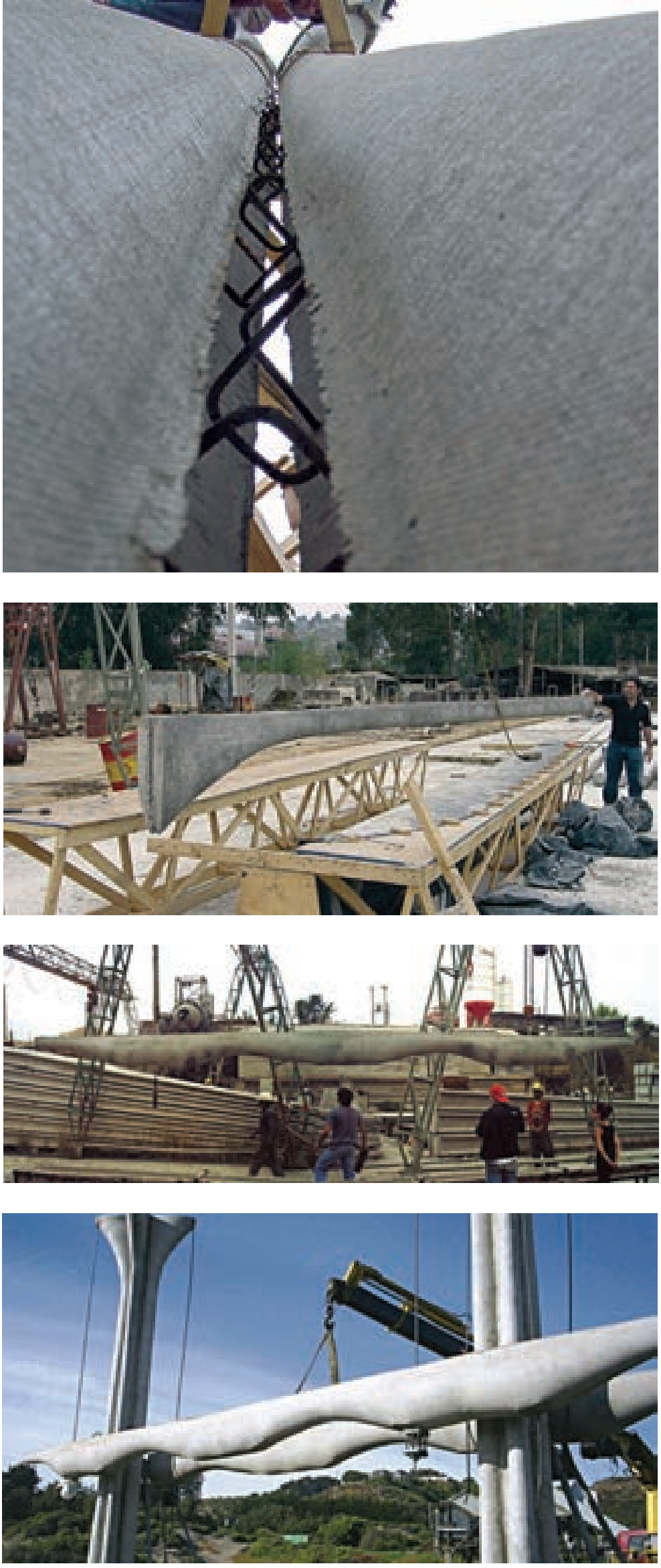

Montaje de la columna compuesta en la duna antes del hormigonado del centro Mounting of a composed column in the dune before the pouring of the center

Desencofrado de un componente, columna compuesta

Removing component from framework, composed column

Desencofrado de viga de sección variable para pórtico en planta INDHERCo, tercera colaboración Removing beam from framework with variable section for portico in INDHERCO plant, third collaboration

Montaje de pórtico en Ciudad Abierta, Ritoque, 2005 Portico mounting in Ciudad Abierta, Ritoque, 2005 